\title{
MRI of the Bladder in Patients Suspected of Bladder Tumors
}

\author{
Karen Lind Gandrup'1, Jørgen Nordling², Henrik S. Thomsen ${ }^{1}$ \\ ${ }^{1}$ Department of Diagnostic Radiology, Copenhagen University Hospital Herlev, Copenhagen, Denmark \\ ${ }^{2}$ Department of Urology, Copenhagen University Hospital Herlev, Copenhagen, Denmark \\ Email: karenlindgandrup@gmail.com
}

Received 21 April 2014; revised 10 May 2014; accepted 30 May 2014

Copyright (C) 2014 by authors and Scientific Research Publishing Inc.

This work is licensed under the Creative Commons Attribution International License (CC BY). http://creativecommons.org/licenses/by/4.0/

(c) (i) Open Access

\begin{abstract}
Objective: To prospectively evaluate the use of MRI for the detecting of bladder tumors and the Tstage using T2W, T1W and diffusion-weighted images (DWI). Material and methods: Twenty-eight consecutive patients ( 21 men, 7 women; age range, 20 - 82 years; mean age, 62.8 years) suspected of bladder tumors underwent MRI, flexible cystoscopy and transurethral resection (TURB). The presence of bladder tumor was confirmed by histopathology in 21 patients; 18 patients had pTa, one pT1 and two pT2. The images were reviewed by two uroradiologists. They assigned the presence of a bladder tumor and whether the tumor was non-muscle invasive (Ta and T1) or muscleinvasive (T2, T3 or T4). Results: Compared to the histopathological results, the accuracy for identifying a bladder tumor was $\mathbf{6 0 . 7 \%}$ and $53.7 \%$ for reviewer $A$ and $B$, respectively. The sensitivity and specificity were $66.7 \% / 61.9 \%$ and $57.1 \% / 42.9 \%$. Positive predictive values were $82.6 \%$ / $76.5 \%$. The overall staging was correct in $47.6 \% / 52.5 \%$, but improved on stage-by-stage up to $50 \% / 66.7 \%$. The agreement between the reviewers was moderate in the detecting, staging and location of the tumor (Kappa $=0.47-0.57$ ). Conclusion: A simple MRI using no contrast media, but DWI, cannot replace flexible cystoscopy in the detection of new or recurrent bladder tumors.
\end{abstract}

\section{Keywords}

Urography, Diagnostic Imaging, Hematuria, Magnetic Resonance Imaging, Cystoscopy

\section{Introduction}

Bladder cancer is the most common cancer in the urinary tract and there are approximately 75,000 new cases in the US every year [1]. Routine work-up of patients suspected of bladder cancer at our institution includes flexible cystoscopy and CT-urography (CTU). At the follow-up visits flexible cystoscopy is repeated. This invasive 
procedure is sometimes painful and poses a risk of iatrogenic injury. The procedure is operator-dependent and cannot be reviewed afterwards like CT and MR images. In the clinical management, differentiation between muscle-invasive (MIBT, i.e. stages T2-T4), and non-muscle invasive bladder cancer (NMIBT, i.e. stages Ta and T1), is crucial, since the options for treatment differ. NMIBT is treated by transurethral resection of the bladder (TURB) and with intravesical chemotherapy. Furthermore, all patients undergo follow-up visits [2]. MIBT requires radical cystectomy, chemotherapy, radiation therapy or a combination [3] depending of the stage and the condition of the patient. Tumors are often understaged at clinical examinations [4]. Therefore, a CT of the abdomen and chest is performed after diagnosis of MIBT [5] and before start of treatment.

A MR examination is painless for the patient and could be an alternative to cystoscopy if the patient, e.g. has radiation injuries, infection or in other ways is not able to undergo cystoscopy. Several studies [6]-[12] have shown that diffusion-weighted images (DWI) may be used to detect bladder tumors, and studies regarding staging [13] [14] show promising results. Most of these studies are retrospective, use supplementary dynamic contrast series or have a population of patients with high-stage tumors [6] [8] [15]. At our institution, there is a substantial population of 1500 patients/year that undergo flexible cystoscopy every four months as part of the follow-up visits. Therefore, we undertook an investigation to evaluate the value of a MRI without the use of contrast media, but with the use of DWI and free breathing.

\section{Material and Methods}

\subsection{Ethics}

This study was approved by the Local Committee for Health Research Ethics (No. H-2-2011-148) and by the Danish Data Protection Agency. Written and oral informed consent was obtained from all patients who participated in the study.

\subsection{Study Population}

Patients referred to TURB due to suspicion of first-time or recurrent bladder tumor between August and November 2013 were invited to participate in the study. Exclusion criteria included severe claustrophobia, pregnancy, magnetic medical implants such as cardiac pacemakers and age $<18$ years. A total of 32 consecutive patients were enrolled. Four cancelled or did not show for the examination. The remaining 28 patients underwent MR examination before TURB. The study population was composed of 21 men (75\%) (mean age, 65 years; range, 43 - 82 years) and seven women (mean age, 56.3 years; range, 30 - 74 years). The patient records were reviewed regarding sex, age, previous surgery, symptoms and urological findings at the first visit. The results of the flexible cystoscopy, the TURB and the pathology reports were noted.

\subsection{MR Examination}

All examinations were performed on a 3T Philips Achieva (Best, the Netherlands) using a 6-channel array coil. The patients were asked to drink approximately $500 \mathrm{ml}$ of water an hour before the examination to ensure a filled bladder. They were scanned in prone position with a small pouch under the lower abdomen to compress the fat surrounding the bladder. Ten minutes before the examination, the patients received 1 ml of Hyoscin-butylbromid (Buscopan ${ }^{\circledR}$, Boehringer Ingelheim, Copenhagen, Denmark) in their deltoid or vastus lateralis muscle. No contrast media and no breath hold were used.

First, T2-weighted (T2W) sequences in the axial, sagittal and coronal planes were obtained (repetition time (TR) msec/echo time (TE) msec, 4700 - 4800/80; matrix, $264 \times 176$; section thickness 3 mm; field of view (FOV), $21 \mathrm{~cm}$ ). Then DWI were obtained in the axial plane (TR msec/TE msec, 2100/55; matrix, $180 \times 113$; section thickness, $3 \mathrm{~mm}$; FOV, $18 \mathrm{~cm}$; b-values sec/mm² , 0, 100, 500, 750, 1000). Lastly, a T1-weighted (T1W) sequence in the axial plane was performed (TR msec/TE msec, 540/10; matrix, $200 \times 220$; section thickness, 3 mm; FOV, $20 \mathrm{~cm}$ ). All images were forwarded to PACS (iSite, Phillips, Best, The Netherlands).

\subsection{Image Analysis}

The MR images were evaluated individually by two experienced uroradiologists, who only had information regarding the reason for referral (suspicion of bladder tumor). The detection of a tumor was based on the T2W 
images and DWI together. The T1W images were used to assess lymph node presence and extravesical tumor mass. A questionnaire was used for the review. The detection and location of the bladder tumor was specified using the following options: 1) right side of the bladder, 2) left side, 3) the trigone, 4) posterior wall, 5) anterior wall and 6) the dome. The presence of high signal intensity (SI) on the DWI was noted for each tumor. For the appearance of the bladder, the options were 1) smooth, 2) trabeculation, and 3) ureterocele. The presence of enlarged lymph nodes and bone-marrow metastasis, and whether they had high SI on DWI, was noted. The staging of the bladder tumor was determined as being Ta-T1 or T2, T3 or T4, thereby dividing the tumor into NMIBT and MIBT using the anatomical criteria used by Takeuchi et al. [14]. The apparent diffusion coefficient (ADC) values were measured using a freehand region of interest (ROI) on the ADC map. Figure 1 shows an example of how the ROI was placed.

\subsection{Cystoscopy}

All the patients underwent flexible cystoscopy and MRI. The placement and the appearance of the bladder tumor were noted.

\subsection{Histopathology}

The specimens were reviewed by an uropathologist for the diagnosis including the pT staging and grading. The tumors were graded using the WHO 2004 classification [16] and staged by the UICCC TNM system [17].

\subsection{Statistics}

The statistical analyses were performed using the software "R" and the Statistical Package for Social Sciences, version 20 (SPSS, Chicago, Illinois, USA). In the evaluation of the two reviewers' performance in identifying, staging and locating bladder tumors, kappa statistics were applied. A Kappa value less than 0.20 was poor, 0.21 0.40 fair, 0.41 - 0.60 moderate, 0.61 - 0.80 good and 0.81 - 1 was considered excellent.

\section{Results}

The reason for the referral and the distribution among the pathology stages is shown in Table 1. All 28 patients had bladder biopsies taken at the TURB. Bladder tumors were diagnosed in 21 of the 28 patients (75\%): inflammation in 1 (3.6\%), benign findings (necrosis, no malignancy, cystitis cystica and fibrosis) in 3 (10.7\%), and the remaining 3 patients' biopsies revealed normal cells. The pathological stages were $18 \mathrm{pTa}$ ( 5 high grade, 13 low grade) (Figure 2), 1 pT1 and 2 pT2. The patient with pT1 also had CIS in one of the biopsies.

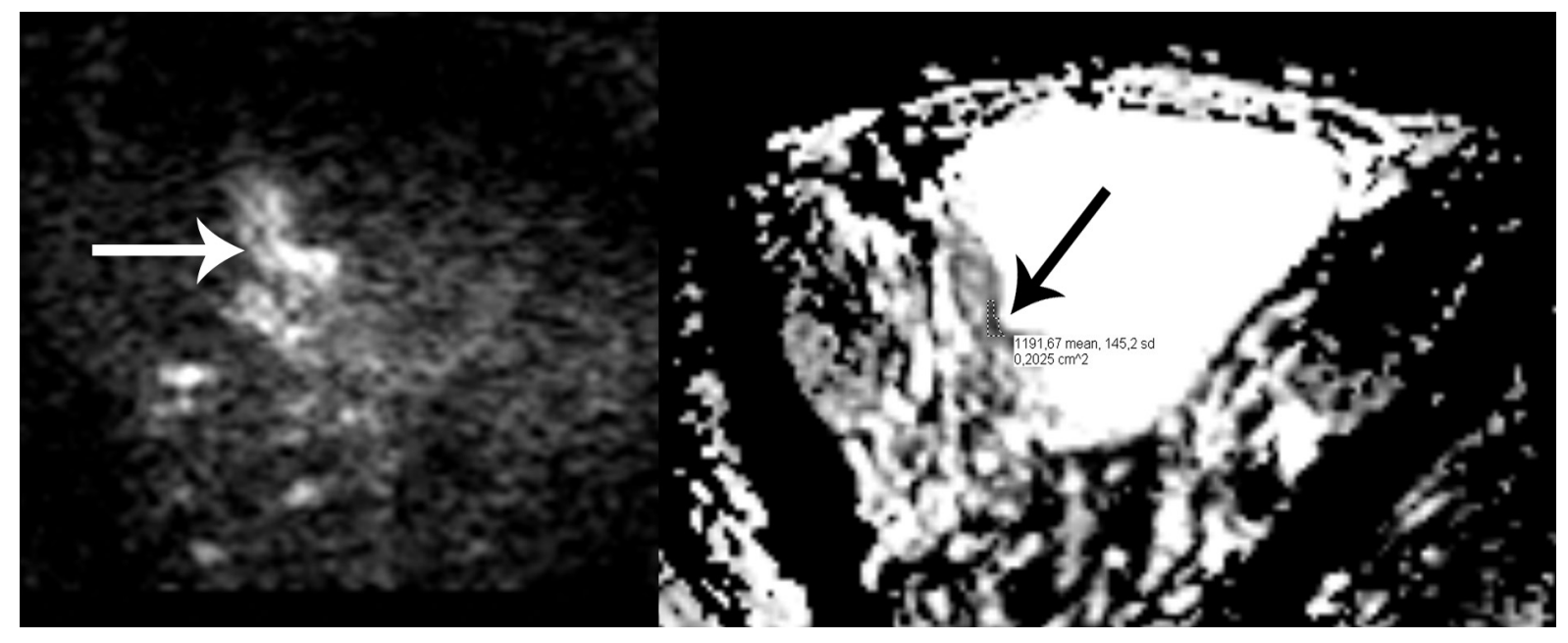

Figure 1. The left image shows high signal intensity (SI) in the tumor (white arrow) on the DWI sequence. The right image shows the corresponding ADC map showing the tumor with low SI (black arrow). The area for measuring the ADC value is also shown. The region of interest (ROI) was placed in the darkest section of the tumor area. Histopathological examination revealed a pT2 tumor. 


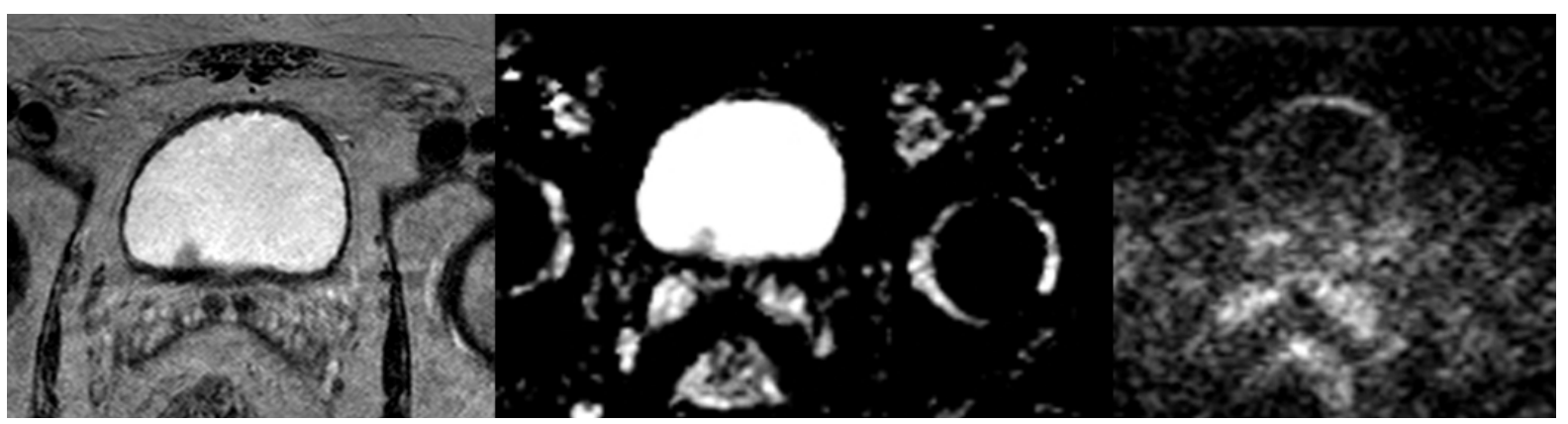

Figure 2. An example of how a pTa tumor appears on axial T2W, DWI and ADC-map. The left image shows a T2W image, the middle an ADC map and the right a DWI. This tumor did not have high SI on DWI.

Table 1. Symptoms grouped by pathology stage.

\begin{tabular}{cccc}
\hline Symptoms & Benign conditions/Normal No. (\%) & NMIBT (pTa, pT1) No. (\%) & MIBT (pT2-pT4) No. (\%) \\
\hline Macroscopic hematuria & $1(3.5)$ & $5(17.9)$ & $1(3.5)$ \\
Microscopic hematuria & $2(7)$ & - & - \\
Recurrent bladder cancer & $3(10.7)$ & $12(42.9)$ & - \\
Incidental finding & - & $1(3.5)$ & - \\
Nocturia & $1(3.5)$ & $18(64.3)$ & $3(10.7)$ \\
Total & $7(25)$ & \\
\hline
\end{tabular}

Of the identified tumors, 15 had a high SI on the DWI $\left(b=1000 \mathrm{sec} / \mathrm{mm}^{2}\right)$. Two tumors did not have high SI: one was a small pTa tumor; the other was a small papilloma with a minimal area of invasion of lamina propria (pT1) and the finding of CIS. Both tumors were recurrent cancers.

The mean and standard deviations of the ADC values $\left(\times 10^{-3} \mathrm{~mm}^{2} / \mathrm{sec}\right)$ were as follows: carcinomas $(\mathrm{n}=15)$, $1.89 \pm 0.53$, the peripherical zone of the prostate $(n=11), 2.70 \pm 0.66$ and the transition zone of the prostate $(n=$ 11), $2.10 \pm 0.48$. There was a statistically significant difference between ADC values of the bladder compared to the peripherical $(p=0.023)$ and central zone of the prostate $(p=0.02)$, respectively.

Both reviewers staged 13 patients to have non-muscle invasive (Ta/T1) and four muscle invasive tumors (T2 or T3). Both reviewers staged one tumor as being T2, but histopathology revealed it to be a biopsy sample of the detrusor muscle with necrotic tissue and no malignancy. The overall staging was $47.6 \% / 52.4 \%$, but improved on stage-to-stage performance up to $66.6 \%$ (Table 2).

The accuracy of reviewer A was $60.7 \%$ and for reviewer B 53.8\%. The sensitivity for detecting tumors were $66.7 \% / 61.9 \%$ for reviewer A and B, respectively. The specificity was $57.1 \% / 42.9 \%$, the positive predictive value (PPV) 82.6\%/76.5\% and the negative predictive value (NPV) 36.4\%/27.3\% for reviewer A and B, respectively.

The agreement between the readers was moderate in both identifying a tumor $(\mathrm{kappa}=0.57)$, the placement ( $k$ appa $=0.47)$ and staging $($ kappa $=0.53)$.

The distribution of identified tumors based on pathology stage appears in Figure 3. The non-invasive papillary carcinoma (pTa) was the most overlooked lesion, accounting for $50 \%$ and $38.8 \%$ for reviewer A and $\mathrm{B}$, respectively.

\section{Discussion}

Studies have reported sensitivities between $40 \%$ - 100\% (Table 3) for identifying bladder tumors. In the various studies, different approaches were used; most of them used both T2W and DWI [8] [10] [15], but some evaluated the sequences separately in identifying the tumor [7] [15]. The sensitivities and specificities in the present study are lower than those studies. Watanabe et al. [15] reported an accuracy of 79\% in detection of tumors in stage T2 or higher, using the same sequences as we did. With DWI alone the sensitivity was low (40\%). Their 


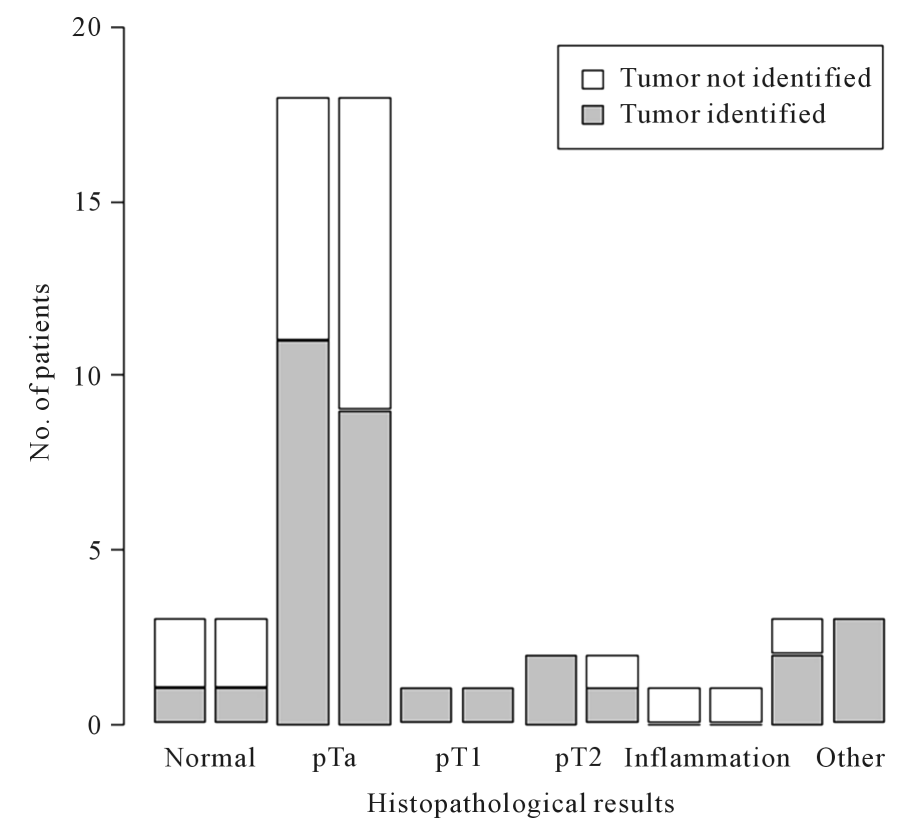

Figure 3. The left bar in each category of pathology represents Reviewer $\mathrm{A}$ and the right bar Reviewer $\mathrm{B}$. The figure illustrates the findings of the MR examinations and the distribution of histopathology. The most overlooked tumor was the non-invasive papilloma (pTa).

Table 2. Comparison between the two readers in staging of bladder tumors.

\begin{tabular}{|c|c|c|c|c|c|c|c|}
\hline \multirow{2}{*}{ Pathology } & & \multicolumn{2}{|c|}{ Correctly staged } & \multicolumn{2}{|c|}{ Overstaged } & \multicolumn{2}{|c|}{ Understaged } \\
\hline & & Reviewer A & Reviewer B & Reviewer A & Reviewer B & Reviewer A & Reviewer B \\
\hline \multirow{2}{*}{ Normal/Benign } & $\%$ & 66.7 & 50 & 33.3 & 50 & - & - \\
\hline & No. & $4 / 6$ & $3 / 6$ & $2 / 6$ & $3 / 6$ & - & - \\
\hline \multirow{2}{*}{ pTa-pT1 } & $\%$ & 61.1 & 50 & 11 & 11 & 38.9 & 44.4 \\
\hline & No. & $11 / 18$ & $9 / 18$ & $2 / 18$ & $2 / 18$ & $7 / 18$ & $8 / 18$ \\
\hline \multirow{2}{*}{ pT2 } & $\%$ & 50 & 100 & 50 & 0 & - & - \\
\hline & No. & $1 / 2$ & $2 / 2$ & $1 / 2$ & 0 & - & - \\
\hline \multirow{2}{*}{ Overall } & $\%$ & 52.4 & 47.6 & 14.3 & 14.3 & $33.3^{\mathrm{a}}$ & 38.1 \\
\hline & No. & $11 / 21$ & $10 / 21$ & $3 / 21$ & $3 / 21$ & $7 / 21^{\mathrm{a}}$ & $8 / 21$ \\
\hline
\end{tabular}

${ }^{\mathrm{a}}$ The tumor was not identified on MRI.

study was retrospective, had a smaller number of patients included and MRI was performed after biopsies. Our population included 21 patients with carcinoma and $64.3 \%$ of these were pTa tumors. This is a high percentage of low stage tumors. Compared with other studies (Table 3), the tumors in the present study were smaller and at a lower stage. In the prospective study by Abou-Al-Ghar [10], the prevalence of MIBT was $75.5 \%$, the sensitivity (98.1\%), specificity (92.3\%) and accuracy (97\%) were high. The low prevalence of MIBT may be the reason for the poor results in detecting tumors in the current study. However, as up to $70 \%$ of first-time bladder tumors are diagnosed as being NMIBT and there are many recurrences in this patient group [18], our study population is a good representation of what the clinicians encounter in their daily practice.

Correct staging of the bladder tumors is crucial for the correct choice of treatment. Our results show that in approximately $50 \%$ of the patients the staging was correct. It improved up to $66 \%$ when differentiating between NMIBT 
Table 3. A summarized table of MR studies and bladder tumor detection.

\begin{tabular}{|c|c|c|c|c|c|c|}
\hline Author & Study type & Tesla & MR type & No pt. & Statistics $^{\mathrm{a}}(\%)$ & $\begin{array}{c}\mathrm{ADC} \\
\left(\times 10^{-3} \mathrm{~mm}^{2} / \mathrm{sec}\right)\end{array}$ \\
\hline Present study & Prospective & 3 & $\begin{array}{l}\text { T2W, T1W, } \\
\text { DWI }\end{array}$ & 28 & Sens: 61.9 - 66.7 Spec: 42.9 - 57.1 & $1.89 \pm 0.53$ \\
\hline Wu et al. [9] 2013 & Prospective & 3 & T2, DWI & 362 & $\begin{array}{l}\text { T2 + DWI: } \\
\text { Sens: } 89 \text { - } 94 \text { Spec: } 93 \text { - } 100 \\
\text { Accuracy: } 92 \text { - } 98\end{array}$ & - \\
\hline Kobayashi et al. [7] 2011 & Prospective & 1.5 & T2, DW & 104 & $\begin{array}{l}\text { DWI sens: } 91.3-92.0 \\
\text { T2 sens: } 89.4 \text { - } 91.0\end{array}$ & $0.39-2.07$ \\
\hline Avcu et al. [8] 2011 & Prospective & 1.5 & T2, DWI & $\begin{array}{l}63 \text { patients } \\
+20 \text { healthy } \\
\text { controls }\end{array}$ & $\begin{array}{l}\text { Sens: } 100.0 \text { Spec: } 76.5 \\
\text { PPV: } 92.0 \text { NPV: } 100.0 \\
\text { Accuracy: } 93.7\end{array}$ & $1.07 \pm 0.26$ \\
\hline Abou-El-Ghar et al. [10] 2009 & Prospective & 1.5 & T2, DWI & 130 & $\begin{array}{l}\text { Sens: } 98.1 \text { Spec: } 92.3 \\
\text { PPV: } 100 \text { NPV: } 92.3 \text { Accuracy: } 97\end{array}$ & - \\
\hline Watanabe et al. [15] 2009 & Retrospective & 1.5 & $\begin{array}{l}\text { T1, T2, DW, } \\
\text { Contrast series }\end{array}$ & 18 & $\begin{array}{l}\text { T1W + T2W + DWI: } \\
\text { Sens: } 40.0 \text { Spec: } 93.0\end{array}$ & - \\
\hline El-Assmy et al. [12] 2008 & Prospective & 1.5 & T2, DWI & 43 & Sens: 100.0 PPV: 100.0 & $1.40 \pm 0.51$ \\
\hline El-Assmy et al. [11] 2009 & Prospective & 1.5 & T2, DWI & 106 & $\begin{array}{l}\text { DWI: Sens: 98.1, PPV: } 100 \\
\text { T2: Sens: 96.2 PPV: } 100\end{array}$ & - \\
\hline Matsuki et al. [6] 2007b & Retrospective & 1.5 & DWI & 15 & $\begin{array}{l}\text { Sens: } 100.0 \\
\text { Spec: } 100.0^{\mathrm{b}}\end{array}$ & $1.18 \pm 0.21$ \\
\hline
\end{tabular}

${ }^{\mathrm{a}}$ Sens: Sensitivity; Spec: Specificity; PPV: positive predictive value; NPV: negative predictive value; ${ }^{\mathrm{b}} \mathrm{MR}$ performed after biopsy.

and MIBT (Table 2). Tekes et al. [13] reported overstaging as the most common error in 32\% with an overall accuracy at 62\%. Their results also improved, up to 85\%, when differentiating between NMIBT and MIBT. Their study used contrast-enhanced series and no DWI. Takeuchi et al. [14] showed an added effect of using DWI; it improved accuracy in staging from 67\%, based on T2W alone, up to $88 \%$ using DWI and T2W images. The sensitivity of detection of pT2 tumors or higher did not increase which is explained by the thin structure of the muscle layers on DWI, which makes it difficult to distinguish between NMIBT and MIBT.

The mean ADC value in our study was higher than other studies (Table 3), but there was still a statistically significant difference from the normal tissue of the prostate in accordance with Matsuki et al. [6]. DWI has found uses in genitourinary imaging, but the variability of the measured ADC values are high between studies in different pelvic organs [19] due to both technical issues and methods to place ROI for measurements. Therefore, until more uniform measurements are archived, the DWI and ADC map should only be used for diagnoses of bladder tumors and not for distinguishing between malignant and benign pathology.

In a study by Tekes et al. [13] evaluating the ability of MRI in staging bladder tumors without DWI, but with enhanced and unenhanced sequences, the agreement among reviewers was good (kappa $=0.80)$ and accuracy in differentiating between invasive and non-invasive was 82\% - 85\%. Takeuchi et al. [14] used dynamic contrast sequences along with T2W and DWI, and reported an accuracy of 88\% for T2W plus DWI. With the contrast series included, the accuracy was 92\%. This shows that adding additional information through contrast-enhanced sequences can help the reviewers. The present study does not include contrast-enhanced imaging, as we wanted to test an easy and fast way of performing MRI of the bladder. The reader agreement was moderate in both identifying, staging and locating the tumor. The locating of the tumor is difficult because of the elasticity of the bladder tissue, and the different degrees of filling of the bladder at the MRI, flexible and rigid cystoscopy procedures [20].

In a recent study by El-Assmy [21] involving 47 patients who previously had undergone TURB for a superficial cancer, the use of MRI for follow-up was investigated. The results were promising with a sensitivity of 91.6\%, specificity 91.3\%, PPV 91.6\% and NPV of 91.3\% using DWI. Thus, there may be a future for MRI in 
these patients with the right MR protocol. Previously, difficulties in distinguishing residual cancer from changes like inflammation and fibrosis after TURB have been reported [22] [23]. Our findings are in accordance.

Limitations of the study were the small numbers of patients, and that the distribution of the T-stages was uneven with a large number of pTa-pT1 and a small numbers of pT2.

We were not able to establish the radiologic-cystoscopy correlation regarding location of the bladder because the urologists did not use a standard questionnaire during cystoscopy, but instead described the location by words. The strength is that we prospectively and consecutively included patients in a population with many recurrent bladder tumors with low T-stages which have not been done before; previous studies have been retrospective or have had a population with higher T-stage tumors.

The literature mentioned in this paper show that the accuracy of both detection and staging of the bladder tumors increases when adding DWI, but even more when adding contrast-media series. Our study was performed on a limited group of patients who underwent an easy-to-perform MRI without contrast media, but with T1W, T2W and DWI sequences, thereby making the examination easier, quicker and without potential adverse effects to the contrast media. However, the study results show low sensitivity, specificity and accuracy and are not adequate to start using MRI of the bladder in the work-up of patients with suspected bladder tumors. More studies are needed in order to determine if this kind of MRI of the bladder is feasible in the work-up of patients suspected for bladder tumors in a population with a high percentage of pTa and pT1 stage tumors.

\section{Conclusion}

In conclusion, our results show that MRI performed on a 3-Tesla scanner using only T2W, T1W and DWI cannot be used as an alternative to flexible cystoscopy in the detecting and staging of bladder tumors.

\section{References}

[1] Siegel, R., Ma, J., Zou, Z. and Jemal, A. (2014) Cancer Statistics 2014. CA: A Cancer Journal for Clinicians, 64, 9-29. http://dx.doi.org/10.3322/caac.21208

[2] Babjuk, M., Oosterlinck, W., Sylvester, R., Kaasinen, E., Böhle, A., Palou-Redorta, J., et al. (2011) EAU Guidelines on Non-Muscle-Invasive Urothelial Carcinoma of the Bladder, the 2011 Update. European Urology, 59, 997-1008. http://dx.doi.org/10.1016/j.eururo.2011.03.017

[3] Stenzl, A., Cowan, N.C., De Santis, M., Kuczyk, M.A., Merseburger, A.S., Ribal, M.J., et al. (2011) Treatment of Muscle-Invasive and Metastatic Bladder Cancer: Update of the EAU Guidelines. European Urology, 59, 1009-1018. http://dx.doi.org/10.1016/j.eururo.2011.03.023

[4] Jacobs, B.L., Lee, C.T. and Montie, J.E. (2010) Bladder Cancer in 2010: How Far Have We Come? CA: A Cancer Journal for Clinicians, 60, 244-272. http://dx.doi.org/10.3322/caac.20077

[5] Zhang, J., Gerst, S., Lefkowitz, R.A. and Bach, A. (2007) Imaging of Bladder Cancer. Radiologic Clinics of North America, 45, 183-205. http://dx.doi.org/10.1016/j.rcl.2006.10.005

[6] Matsuki, M., Inada, Y., Tatsugami, F., Tanikake, M., Narabayashi, I. and Katsuoka, Y. (2007) Diffusion-Weighted MR Imaging for Urinary Bladder Carcinoma: Initial Results. European Urology, 17, 201-204. http://dx.doi.org/10.1007/s00330-006-0281-7

[7] Kobayashi, S., Koga, F. and Yoshida, S., et al. (2011) Diagnostic Performance of Diffusion-Weighted Magnetic Resonance Imaging in Bladder Cancer: Potential Utility of Apparent Diffusion Coefficient Values as a Biomarker to Predict Clinical Aggressiveness. European Urology, 21, 2178-2186. http://dx.doi.org/10.1007/s00330-011-2174-7

[8] Avcu, S., Koseoglu, M.N., Ceylan, K., Bulut, M.D., Dbulutand, M. and Unal, O. (2011) The Value of DiffusionWeighted MRI in the Diagnosis of Malignant and Benign Urinary Bladder Lesions. The British Journal of Radiology, 84, 875-882. http://dx.doi.org/10.1259/bjr/30591350

[9] Wu, L.-M., Chen, X.-X., Xu, J.-R., Zhang, X.-F., Suo, S.-T., Yao, Q.-Y., et al. (2013) Clinical Value of T2-Weighted Imaging Combined with Diffusion-Weighted Imaging in Preoperative T Staging of Urinary Bladder Cancer: A LargeScale, Multiobserver Prospective Study on 3.0-T MRI. Academic Radiology, 20, 939-946. http://dx.doi.org/10.1016/j.acra.2013.02.012

[10] Abou-El-Ghar, M. and El-Assmy, A. (2009) Bladder Cancer: Diagnosis with Diffusion-weighted MR Imaging in Patients with Gross Hematuria. Radiology, 251, 415-421. http://dx.doi.org/10.1148/radiol.2503080723

[11] El-Assmy, A., Abou-El-Ghar, M.E., Mosbah, A., El-Nahas, A.R., Refaie, H.F., Hekal, I.A., et al. (2009) Bladder Tumour Staging: Comparison of Diffusion- and T2-Weighted MR Imaging. European Urology, 19, 1575-1581. 
http://dx.doi.org/10.1007/s00330-009-1340-7

[12] El-Assmy, A., Abou-El-Ghar, M.E., Refaie, H.F. and El-Diasty, T. (2008) Diffusion-Weighted MR Imaging in Diagnosis of Superficial and Invasive Urinary Bladder Carcinoma: A Preliminary Prospective Study. Scientific World Journal, 8, 364-370. http://dx.doi.org/10.1100/tsw.2008.55

[13] Tekes, A., Kamel, I., Imam, K., Szarf, G., Schoenberg, M., Nasir, K., et al. (2005) Dynamic MRI of Bladder Cancer: Evaluation of Staging Accuracy. American Journal of Roentgenology, 184, 121-127. http://dx.doi.org/10.2214/ajr.184.1.01840121

[14] Takeuchi, M., Sasaki, S., Ito, M., Okada, S., Takahashi, S., Kawai, T., et al. (2009) Urinary Bladder Cancer: Diffusionweighted MR Imaging-Accuracy for Diagnosing T Stage and Estimating Histologic Grade. Radiology, 251, 112-121. http://dx.doi.org/10.1148/radiol.2511080873

[15] Watanabe, H., Kanematsu, M., Kondo, H., Goshima, S., Tsuge, Y., Onozuka, M., et al. (2009) Preoperative T Staging of Urinary Bladder Cancer: Does Diffusion-Weighted MRI Have Supplementary Value? American Journal of Roentgenology, 192, 1361-1366. http://dx.doi.org/10.2214/AJR.08.1430

[16] Eble, J., Sauter, G., Epstein, J. and Sesterhenn, I. (2004) Pathology and Genetics of Tumours of the Urinary System and Male Genital Organs. IARC Press, Lyon.

[17] Sobin, L.H., Gospodarowicz, M.K. and Wittekind, C. (2009) International Union against Cancer (UICC): TNM Classification of Malignant Tumours. 7th Edition, Wiley-Blackwell, Chicester.

[18] Wein, A. (2010) Non-Muscle-Invasive Bladder Cancer (Ta, T1, and CIS). In: Kavoussi, L., Novick, A., Partin, A. and Peters, C., Eds., Campbell-Walsh Urology, Elsevier Saunders, Philadelphia, 2335-2354.

[19] Thoeny, H.C., Forstner, R. and De Keyzer, F. (2012) Genitourinary Applications of Diffusion-Weighted MR Imaging in the Pelvis. Radiology, 263, 326-342. http://dx.doi.org/10.1148/radiol.12110446

[20] Barentsz, J.O., Jager, G.J., Witjes, J.A. and Ruijs, J.H. (1996) Primary Staging of Urinary Bladder Carcinoma: The Role of MRI and a Comparison with CT. European Radiology, 6, 129-133. http://dx.doi.org/10.1007/BF00181125

[21] El-Assmy, A., Abou-El-Ghar, M.E., Refaie, H.F., Mosbah, A. and El-Diasty, T. (2012) Diffusion-Weighted Magnetic Resonance Imaging in Follow-Up of Superficial Urinary Bladder Carcinoma after Transurethral Resection: Initial Experience. BJU International, 110, E622-E627. http://dx.doi.org/10.1111/j.1464-410X.2012.11345.X

[22] Dobson, M.J., Carrington, B.M., Collins, C.D., Ryder, W.D., Read, G., Hutchinson, C.E., et al. (2001) The Assessment of Irradiated Bladder Carcinoma Using Dynamic Contrast-Enhanced MR Imaging. Clinical Radiology, 56, 94-98. http://dx.doi.org/10.1053/crad.2000.0560

[23] Purysko, A.S., Leão Filho, H.M. and Herts, B.R. (2012) Radiologic Imaging of Patients with Bladder Cancer. Seminars in Oncology, 39, 543-558. http://dx.doi.org/10.1053/j.seminoncol.2012.08.010. 
Scientific Research Publishing (SCIRP) is one of the largest Open Access journal publishers. It is currently publishing more than 200 open access, online, peer-reviewed journals covering a wide range of academic disciplines. SCIRP serves the worldwide academic communities and contributes to the progress and application of science with its publication.

Other selected journals from SCIRP are listed as below. Submit your manuscript to us via either submit@scirp.org or Online Submission Portal.
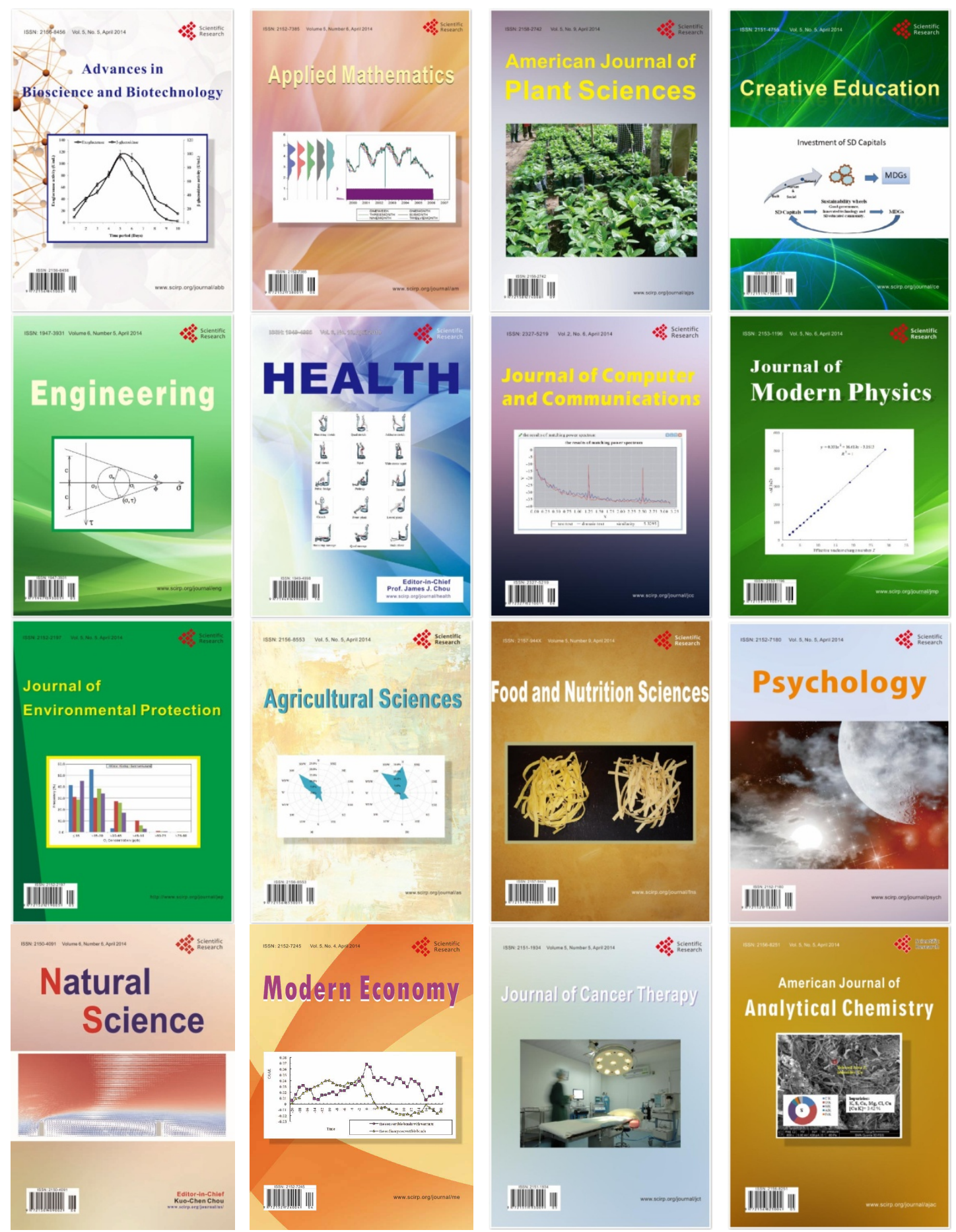